\title{
ENFERMEIRAS NA GESTÃO DE UMA UNIDADE DE CUIDADOS DE PACIENTES PÓS COVID-19
}

\author{
Terezinha de Fátima Gorreis', Rosane Maria Sordi ${ }^{12}$, Rozemy Magda Vieira Gonçalves'
}

\section{(E- mail: rdriemeier@hcpa.edu.br)}

\section{1-Hospital de Clinicas de Porto Alegre}

2-Universidade Federal do Rio Grande do Sul

A enfermagem tem um papel importante no combate ao coronavírus e na reabilitação dos pacientes com sequelas remanescentes pela doença. No 6o andar Norte do Hospital de Clínicas de Porto Alegre (HCPA) existem seis leitos na Unidade de Cuidados Especiais (UCE) para Pneumologia que admite atualmente também pacientes com sequelas e doenças pulmonares pós Covid-19. Esse trabalho relata a experiência de enfermeiras que atuam no processo de gestão de uma UCE de pacientes pós COVID-19, ressaltando seu protagonismo nas tomadas de decisões em um hospital universitário do Sul do Brasil. Realizaram-se reuniões para a tomada de decisões, criação de protocolos e fluxos com participação ativa do enfermeiro nas questões relacionadas à assistência direta, e desenvolvimento de adaptações no processo de enfermagem com ordenamento de novos fluxos e rotinas. O espaço físico foi estruturado, considerando-se o alto risco de transmissibilidade e diversas sequelas decorrentes da doença. Treinamentos de profissionais foram intensificados com readequação do dimensionamento conforme a complexidade do serviço, formando-se uma equipe de profissionais com experiência em cuidados críticos. Houve treinamentos para o desenvolvimento de conhecimentos e habilidades anteriormente aos primeiros casos, que foram mantidos sistematicamente. Observou-se preocupação dos enfermeiros com relação à saúde mental dos profissionais atuantes nesta unidade, com a percepção que a relação com os pacientes, críticos ou difíceis, quer seja pela postura, quer seja pela falta de manejo e lida, muitas vezes associados aos acompanhantes e/ou parentes também tem sido citado como fonte de desordem mental ou psíquica entre a classe de profissionais de enfermagem. Enfatiza-se o alicerce nas evidências científicas e recomendações dos órgãos competentes em nível mundial e nacional para a estruturação da UCE a fim de atender os pacientes pós COVID-19. Destaca-se o protagonismo do enfermeiro em todas as interfaces, o qual assume papel fundamental desde a composição das comissões, perpassando pelo planejamento e funcionamento da estrutura física, gestão de recursos humanos, construção de protocolos e fluxos de cuidado, além de atuar diretamente na assistência. Os enfermeiros desenvolvem papel essencial na reabilitação desses pacientes para a melhoria da qualidade de vida e na educação permanente da equipe, pacientes e familiares.

Nota da Comissão Organizadora: O presente resumo foi aceito para publicação no XIII Simpósio Brasileiro de Microbiologia Aplicada em caráter de excepcionalidade devido à pandemia de COVID-19

Palavras - chave: Enfermagem; Liderança; Gestão de riscos; Administração dos cuidados ao paciente; Infecções por coronavírus 